\title{
Prophylactic Use of Intraumbilical Vein Oxytocin in the Management of Third Stage of Labor
}

\author{
Mohamed Ahmed Mohamed*, Hassan I. Mohamed, Osama Ali, Ahmed Shabaan \\ Obstetrics and Gynecology department, Faculty of Medicine, Al-Azhar University \\ *Corresponding author: Mohamed Ahmed Mohamed, E-Mail:dr.osman89@ gmail.com, Mobile: 01111211623
}

\begin{abstract}
Background: the third stage of labor is defined as the period of time between delivery of the fetus and delivery of the placenta. The most common complication accompanying this stage is postpartum hemorrhage (PPH) and prolonged third stage of labor owing to placenta retention and uterine atony are among the underlying cause of most cases of PPH. The duration of the third stage of labor is 5-15 min. Aim: to assess the efficacy of intraumbilical vein oxytocin in reducing duration of third stage of labour and the amount of blood loss.

Patients and Methods: this study included 150 women attending the delivery room of Department of Obstetrics and Gynecology which was divided according to the inclusion and exclusion criteria into two groups:

- Group A (study group): include 75 cases which received $10 \mathrm{IU}$ ( $1 \mathrm{ml})$ of oxytocin in umbilical vein.

- Group B (control group): include 75 cases which received $1 \mathrm{ml}$ of saline in umbilical vein.

Results: the time of third stage took seconds in each group with no statistically significant difference detected $(\mathrm{p}>0.05)$.

Conclusion: intra-umbilical oxytocin is a useful alternative in patients where methylergometrine is contraindicated or in cases where intravenous fluids need to be restricted. For optimum effect, rapid injection immediately after clamping of the cord is essential.
\end{abstract}

Keywords: intraumblical oxytocin, third stage of labour, postpartum hemorrhage

\section{Introduction}

The third stage of labor is defined as the period of time between delivery of the fetus and delivery of the placenta. The most common complication accompanying this stage is postpartum hemorrhage (PPH) and prolonged third stage of labor owing to placenta retention and uterine atony are among the underlying cause of most cases of PPH. The duration of the third stage of labor is $5-15 \mathrm{~min}^{(\mathbf{1})}$.

Postpartum hemorrhage is a major cause of maternal death worldwide. It is the cause of approximately half of all maternal deaths in developing countries ${ }^{(2)}$. and even in many developed countries. It is one of the major causes of admission of mothers to intensive care units ${ }^{(3)}$.

The common causes of postpartum hemorrhage including bleeding from the site of implantation of the placenta, genital and nearby organs trauma or both of them ${ }^{(4)}$.

Hemostasis of placental site is first established with the contraction of myometrium and thrombosis of the vessel lumens. As a result, parts attached to the placenta or large blood clots which impede efficient contracting of myometrium, can disrupt hemostasis in the placental site ${ }^{(5)}$.

Aim of the Work

This is a randomized control study aims to assess the efficacy of intraumbilical vein oxytocin in reducing duration of third stage of labor and the amount of blood loss.

Patients and Methods

Type of Study: Randomized controlled study. Study Settings: Al-Galaa Teaching Maternity Hospital.

Study Duration: 6 months (from April 2017 September 2017).

\section{Study Population:}

This study included 150 women attending the delivery room of Department of Obstetrics and Gynecology which was divided according to the inclusion and exclusion criteria into two groups:

- Group A (study group: include 75 cases which received $10 \mathrm{IU}(1 \mathrm{ml})$ of oxytocin in umbilical vein). 
- Group B (control group: include 75 cases which received $1 \mathrm{ml}$ of saline in umbilical vein).

\section{The inclusion criteria:}

1. Uncomplicated a live single pregnancy.

2. 37 to 41 weeks gestational age.

3. Vertex presentation.

4. Primigravida and multipara

5. Spontaneous and induced onset of labour.

6. Normal vaginal delivery.

\section{The exclusion criteria:}

1. Placenta Previa.

2. Placental Abruption.

3. Previous history of postpartum haemorrhage.

4. Hemoglobin less than $7 \mathrm{~g} / \mathrm{dL}$.

5. Known coagulation disorders.

6. Temperature higher than $38^{\circ} \mathrm{C}$ during labor (at two consecutive readings).

7. Prolonged Labor $(>20 \mathrm{~h})$.

8. Accelerated Labor $(<3 \mathrm{~h})$.

9. Polyhydramnios .

10. Multiple Gestations

11. Known uterine anomalies .

12. Abnormal placental adhesion

13. Forceps or Vacuum delivery.
14. Painless Labor with Epidural Anaethesia.

15. History of Cesarean delivery or any uterine scar.

Ethical issues:

The hospital ethics committee approved the study.

\section{Consent Process:}

The population sample under study was instructed about research protocol and informed consent is granted from each participant before randomization.

\section{Data analysis:}

Data was collected, tabulated, then analyzed using IBM $\odot$ SPSS $\odot$ Statistics version 22 (IBM@ C Corp., Armonk, NY).

Normally distributed numerical data was presented as mean and SD, and skewed data as median and interquartile range. Qualitative data was presented as number and percentage.

Comparison of normally distributed numerical data was done using the unpaired Student $t$ test. Skewed data was compared using the MannWhitney $U$ test. Categorical data were compared using the chi-squared test, or Fisher's exact test when appropriate.

A two-sided p-value <0.05 were considered statistically significant.

\section{Results}

Table1: Obstetric history of patients in both study groups (age):

\begin{tabular}{cccccc}
\hline Variable & Study group $(\mathbf{n = 7 5})$ & Control group $(\mathbf{n = 7 5})$ & t & Df & p-value $\llbracket$ \\
\hline Age (years) & $27 \pm 5$ & $28 \pm 6$ & -0.868 & 148 & 0.387 \\
\hline
\end{tabular}

Table2: Obstetric history of patients in both study groups (parity):

\begin{tabular}{|c|c|c|c|c|c|c|c|c|}
\hline \multirow[t]{2}{*}{ Variable } & & \multicolumn{2}{|c|}{ Study group $(n=75)$} & \multicolumn{2}{|c|}{ Control group $(n=75)$} & \multirow[b]{2}{*}{$\chi^{2}$} & \multirow[b]{2}{*}{ Df } & \multirow[b]{2}{*}{ p-valued } \\
\hline & & $\mathbf{N}$ & $\%$ & $\mathbf{N}$ & $\%$ & & & \\
\hline \multirow[t]{6}{*}{ Parity } & $P G$ & 33 & $44.0 \%$ & 27 & $36.0 \%$ & 1.249 & 1 & 0.264 \\
\hline & $P 1$ & 15 & $20.0 \%$ & 16 & $21.3 \%$ & & & \\
\hline & $P 2$ & 14 & $18.7 \%$ & 12 & $16.0 \%$ & & & \\
\hline & $P 3$ & 5 & $6.7 \%$ & 11 & $14.7 \%$ & & & \\
\hline & P4 & 8 & $10.7 \%$ & 9 & $12.0 \%$ & & & \\
\hline & $\geq P 5$ & 0 & $0.0 \%$ & 0 & $0.0 \%$ & & & \\
\hline \multirow[t]{4}{*}{ Previous abortions } & Nil & 64 & $85.3 \%$ & 66 & $88.0 \%$ & 0.372 & 1 & 0.542 \\
\hline & One & 8 & $10.7 \%$ & 6 & $8.0 \%$ & & & \\
\hline & Two & 1 & $1.3 \%$ & 3 & $4.0 \%$ & & & \\
\hline & Three & 2 & $2.7 \%$ & 0 & $0.0 \%$ & & & \\
\hline
\end{tabular}

The two tables show that there was no statistically significant difference detected between the 2 groups concerning, age and parity $(p>0.05)$. 
Table 3: Time of third stage took in mins. in each group.

\begin{tabular}{ll}
\hline & \multicolumn{1}{c}{ Mean time to spontaneous placental separation (min) } \\
\hline Group & Estimate \\
\hline Study group $(\mathrm{n}=75)$ & 2.39 \\
Control group $(\mathrm{n}=75)$ & 1.93 \\
Overall $(\mathrm{n}=150)$ & 2.16 \\
\hline Log-rank test & \\
$X^{2}$ & 1.803 \\
$D f$ & 1 \\
$p$-value & 0.179 \\
\hline
\end{tabular}

This table shows the time of third stage took in seconds in each group with no statistically significant difference detected ( $p>0.05)$.

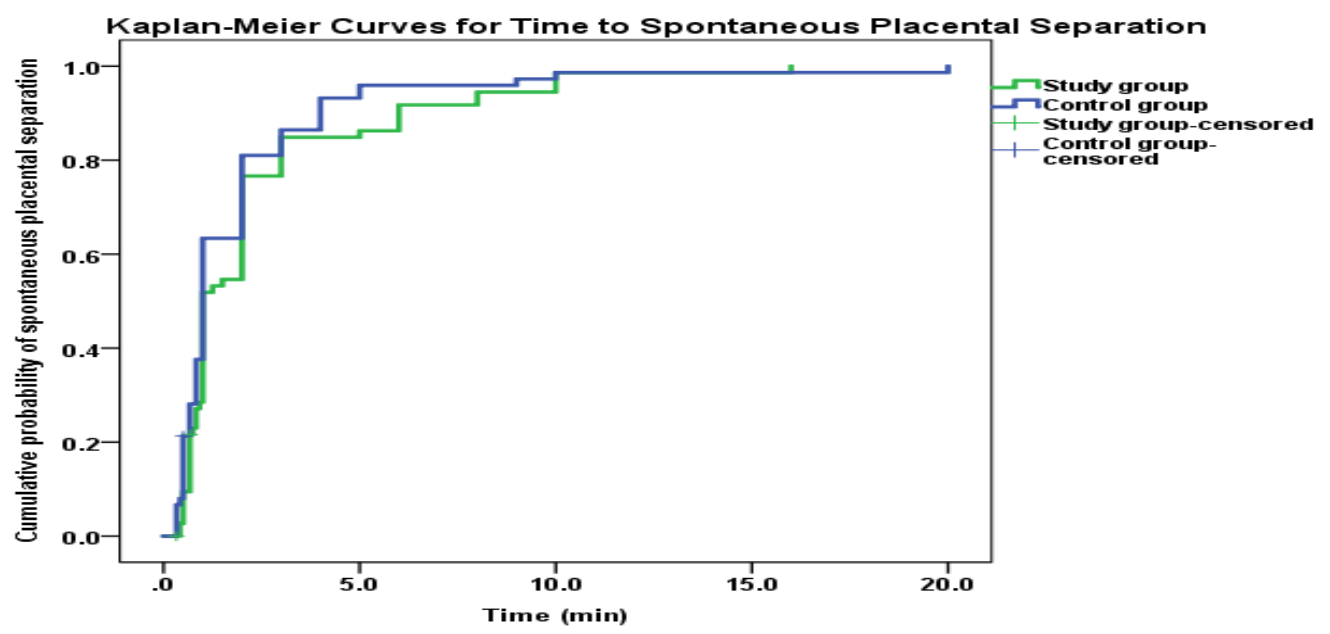

Fig. 1: Kaplan-Meier curves for time to spontaneous placental separation in both study groups.

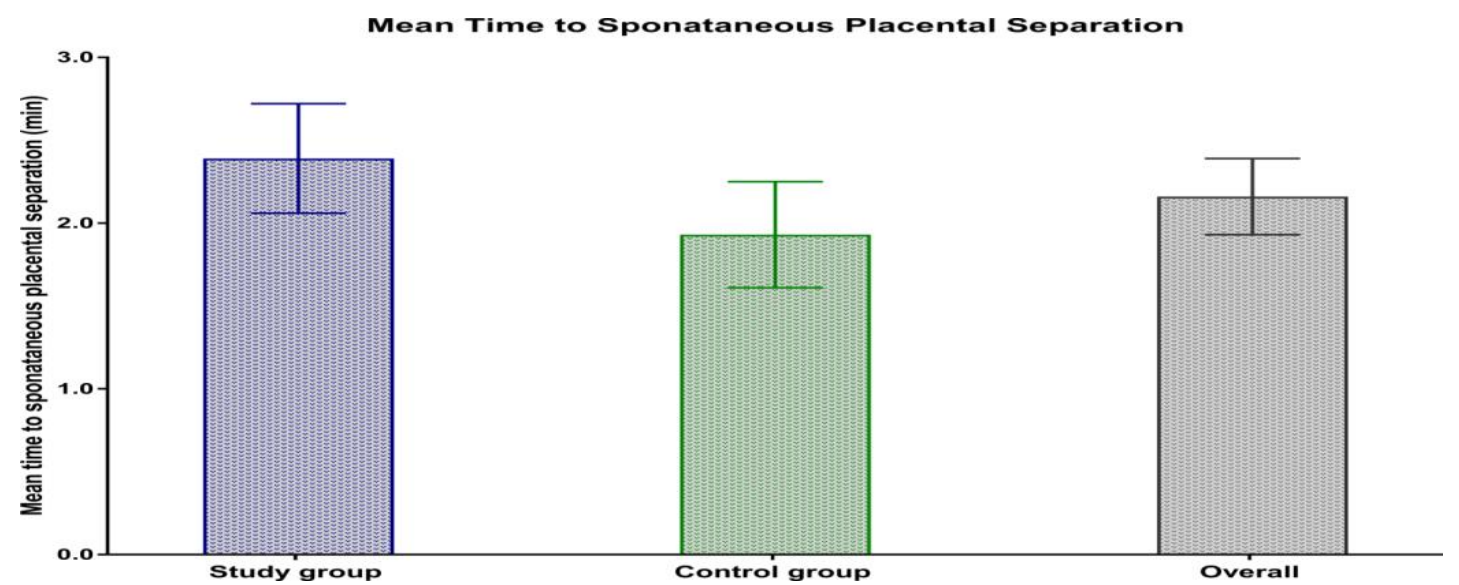

Fig. 2: Mean time to spontaneous placental separation. Error bars represent the standard error of the mean.

Table5 : Blood lost in $\mathrm{ml}$ in third stage of labour in each group. 
Prophylactic Use of Intraumbilical Vein Oxytocin in the Management of Third Stage of Labor

\begin{tabular}{lccccc}
\hline \multicolumn{1}{c}{ Variable } & Study group $(\mathbf{n}=\mathbf{7 5})$ & Control group $(\mathbf{n}=\mathbf{7 5})$ & $\mathbf{U}$ & $\mathbf{Z}$ & p-valueIl \\
\hline $\begin{array}{l}\text { Estimated blood } \\
\text { loss }(\mathrm{ml})\end{array}$ & $200(100-300)$ & $200(100-300)$ & 2793.0 & -0.074 & 0.941 \\
\hline
\end{tabular}

This table shows the amount of blood loss in $\mathrm{ml}$ in third stage of labour in each group with no statistically significant difference detected $(\mathrm{p}>0.05)$.

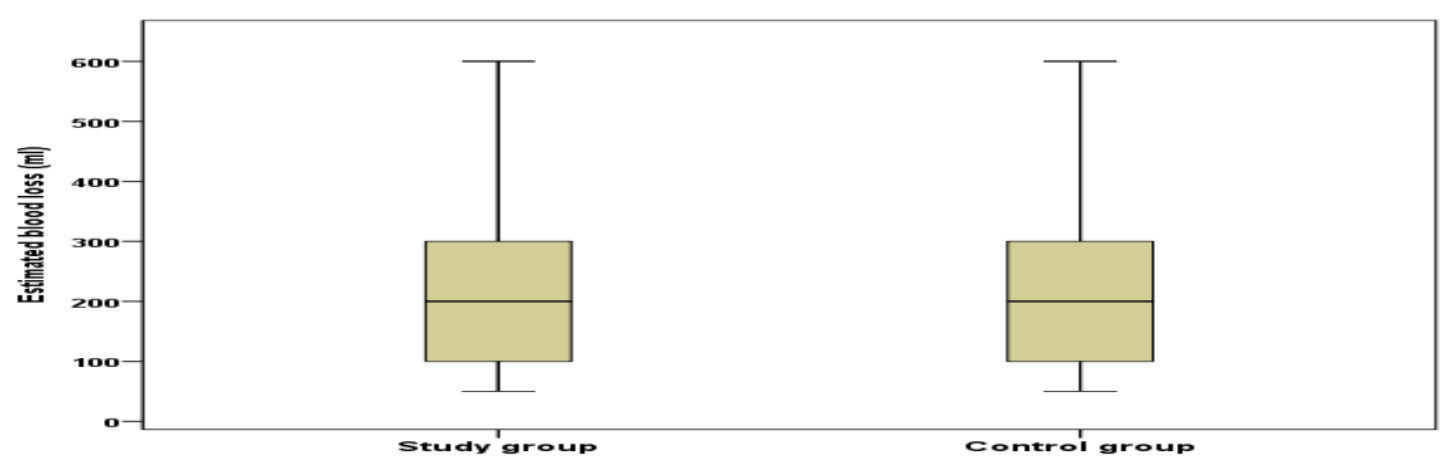

Fig. 3: Blood lost in $\mathrm{ml}$ in third stage of labour in each group.

Table 6 : Hemoglobin pre-partum in gm/dl in each group.

\begin{tabular}{lccccc}
\hline \multicolumn{1}{c}{ Variable } & Study group $(\mathbf{n}=\mathbf{7 5})$ & Control group $(\mathbf{n}=\mathbf{7 5})$ & T & df & p-valuedl \\
\hline $\begin{array}{l}\text { Pre-delivery hemoglobin } \\
(\mathrm{g} / \mathrm{dl})\end{array}$ & $10.7 \pm 1.0$ & $10.7 \pm 0.9$ & -0.307 & 148 & 0.759 \\
& & & & & \\
\hline
\end{tabular}

This table shows the hemoglobin pre-partum in gm/dl in third stage of labor in each group with no statistically significant difference detected ( $p>0.05)$.

Table 7: Hemoglobin postpartum in $\mathrm{gm} / \mathrm{dl}$ in each group.

\begin{tabular}{cccccc}
\hline Variable & Study group $(\mathbf{n}=\mathbf{7 5})$ & $\begin{array}{c}\text { Control group } \\
(\mathbf{n = 7 5})\end{array}$ & t & Df & p-valued \\
\hline $\begin{array}{c}\text { Post-delivery hemoglobin } \\
\text { (g/dl) }\end{array}$ & $10.4 \pm 1.0$ & $10.5 \pm 0.9$ & 0.705 & 148 & 0.482 \\
\hline
\end{tabular}

This table shows the hemoglobin postpartum in $\mathrm{gm} / \mathrm{dl}$ in third stage of labor in each group with no statistically significant difference detected ( $p>0.05$ ).

Table 8: Drop in hemoglobin in both study groups.

\begin{tabular}{lccccc}
\hline Variable & Study group $(\mathbf{n = 7 5})$ & $\begin{array}{c}\text { Control group } \\
(\mathbf{n = 7 5})\end{array}$ & $\mathbf{U}$ & $\mathbf{Z}$ & p-valuedl \\
\hline Drop in hemoglobin $(\mathrm{g} / \mathrm{dl})$ & 0.3 & 0.2 & 2431 & 1.47 & 0.142 \\
& $(0.2-0.4)$ & $(0.2-0.3)$ & & & 0.1351 \\
\hline $\begin{array}{l}\text { Percentage of drop in } \\
\text { hemoglobin }\end{array}$ & 2.7 & $\begin{array}{c}2.1 \\
(1.8-3.7)\end{array}$ & 2415 & 1.494 & \\
\hline
\end{tabular}

This table shows the drop in hemoglobin in $\mathrm{gm} / \mathrm{dl}$ in third stage of labor in each group with no statistically significant difference detected ( $p>0.05)$.

\section{Discussion}

In our study, there was no statistically significant difference between the two groups according to maternal age and parity In the group A: (the experimental group: 75 women ::10 IU (1mL) oxytocin was injected into the umbilical vein at the most proximal site to the placenta after clamping and cutting of the umbilical cord. In the group B : ( control group:75 women ): $1 \mathrm{~mL}$ normal saline was injected into the umbilical vein at the most proximal site to the placenta after clamping and cutting of the umbilical cord, this is in agreement with Ghulmiyyah et al. ${ }^{\left({ }^{(6)}\right.}$ who used the same drugs which used in this study but on number of the patients more than that in the present study.

Also In our study, there was no statistically significant difference between the two groups regarding to time of third stage took in minutes with mean $2.39 \mathrm{~min}$ in (study group), 
1.93 min in (control group). P value 0.179 . This goes with the results of study carried out by Ghulmiyyah et al. ${ }^{(6)}$ who found mean time of third stage took in minutes 4.1 min ( Study group ), $3.2 \mathrm{~min}$. They believe that this lack of difference may be the result of a type II error; the difference in the mean duration of the third stage of labor between the two groups was only 2 minutes, and their sample size was inadequate to show a difference in this outcome.

In Sharma et al. ${ }^{(7)}$ randomly assigned 958 women into 2 groups. Group I placental cord drainage and group II administration of with delivery of the anterior shoulder or immediately after cord clamping. The third stage had a mean duration of 3.2410 minute in oxytocin intraumblical injection group and 3.20 minutes in cord drainage group with $\mathrm{p}$ value 0.157 . So there was no statistically significant difference between the two groups according to the duration of third stage of labor.

In Ojha and Malla ${ }^{(8)}$ study, there was no difference in the duration of third stage of labour (3.6 vs. $3.7 \mathrm{~min}$ ) between the intraumblical and intramuscular groups.

In our study, there was no statistically significant difference regarding blood loss in the third stage of labor with Mean blood loss was $200 \mathrm{ml}$ in both group, this was in accordance with Dickinson et al. ${ }^{(9)}$.

\section{Conclusion and Recommendations}

Intra-umbilical oxytocin is a useful alternative in patients where methylergometrine is contraindicated or in cases where intravenous fluids need to be restricted. For optimum effect, rapid injection immediately after clamping of the cord is essential . Hence patients requiring cord blood collection, cord segment for blood gases etc, involved a time lapse and were not included in our study. Primigravidas and multigravidas requiring epsiotomy showed fluctuations in the results due to variations in the blood loss. However, intra-umbilical injections can be used in both these groups.

\section{References}

1. Acevedo-Rodriguez A, Mani SK, Handa RJ (2015): "Oxytocin and Estrogen Receptor $\beta$ in the Brain: An Overview". Frontiers Endocrinology, 6:160.

2. Al-Zirqi I, Vangen S, Forsen L et al. (2008): Prevalence and risk factors of severe obstetric haemorrhage. BJOG., 115(10):126572 .

3. American College of Obstetricians and Gynecologists (2006): ACOG practice bulletin: clinical management guidelines for obstetrician gynecologist number 76: postpartum hemorrhage. obstetric and gynecology, 108(4):1039-?.

4. FIGO Guidelines (2012): Prevention and treatment of postpartum hemorrhage in lowresource settings; International Journal of Gynecology and Obstetrics, 117: 108-118.

5. Attilakos G, Psaroudakis D, Ash J et al. (2010): Carbetocin versus oxytocin for the prevention of postpartum haemorrhage following caesarean section: the results of a double-blind randomised trial. BJOG: An International Journal of Obstetrics \& Gynaecology, 117(8), 929-936.

6. Ghulmiyyah LM, Wehbe SA, Saltzman SL, Ehleben C, Sibai BM(2007): Intraumbilical vein injection of oxytocin and the third stage of labor: randomized doubleblind placebo trial. Am J Perinatol .,24:347-52. 7. Sharma JB, Pundir P, Malhotra M (2005): Evaluation of placental drainage as a method of placental delivery in vaginal deliveries. Arch Gynecology \& Obstetric, 271:343-5.

8. Ojha N and Malla D (2007): Active management of third stage of labour by oxytocin: Umbilical vein versus intramuscular use. Nepal Journal of Obstetrics and Gynaecology, 2(1): 13-16.

9. Dickinson JE, Dorota A and Doherty DA (2009): Optimization of third stage Management after second-trimester medical pregnancy termination. Am J Obstet Gynecol., 201:303.1-7. 